Anuario Latinoamericano Ciencias Políticas

y Relaciones Internacionales

vol. 6, 2018

pp. $169-184$

DOI: 10.17951/al.2018.6.169-184

\title{
La frontera misionera en México entre conquista espiritual y territorial
}

\author{
Missionary border in Mexico between spiritual \\ and territorial conquest
}

\author{
Fernando Ciaramitaro* \\ UNIVERSIDAD AUTÓNOMA DE LA CIUDAD DE MÉXICO \\ $\triangle$ fernando.ciaramitaro@uacm.edu.mx \\ https://orcid.org/0000-0002-0299-7057
}

\begin{abstract}
RESUMEN
Frontera y práctica misionera son dos realidades históricas que proceden simultáneamente en la colonización de las Américas. Después de analizar el debate más reciente de la cuestión liminal en el continente americano, el ensayo procura dilucidar, desde una mirada descriptiva y comparativa, el marco misionero fronterizo de México, pensado como espacio social, histórico y geográfico todavía no conquistado de manera permanente. Se tratan tres realidades misioneras: Chiapas, la región yaqui y California.
\end{abstract}

PALABRAS CLAVE: frontera, misión, América, Chiapas, región yaqui, California.

\begin{abstract}
Border and missionary practice are two historical realities that proceed simultaneously in the colonization of the Americas. After analyzing the most recent debate on the liminal issue in the New World, the essay attempts to elucidate, from a descriptive and comparative perspective, the Mexican border missionary framework, thought of as a social, historical and geographical space not yet permanently conquered. Three missionary realities are discussed: Chiapas, the Yaqui region and California.
\end{abstract}

KEYWORDS: border, mission, America, Chiapas, Yaqui region, California.

\footnotetext{
* Es profesor en la Universidad Autónoma de la Ciudad de México e investigador visitante en El Colegio de México. Doctor en Historia por la Universidad de Catania (Italia) y Licenciado en Ciencias Políticas por la Universidad de Palermo (Italia).
} 


\section{Introducción: el confín y la frontera}

Confín y frontera son dos conceptos que se relación con la alteración del paisaje y de la historia que el espacio describe, modificando y delimitando el territorio que poblaciones y comunidades dominan o no. Históricamente, según Fernand Braudel (1988: 301), solo la condición de estar u ocupar de forma permanente un espacio ha significado para el ser humano "empezar a ser". O sea, desde la antigüedad el hombre se ha vinculado a un espacio físico y su dimensión como ser social se expresa en la asociación que conforma o en la polis, conjunto urbano definido por sus confines amurallados. Sin embargo, confín y frontera no son sinónimos, mientras que confín es el límite, o sea la raya aceptada de separación de demarcaciones, "frontera" contiene el sustantivo "frente", la frontera está "frente a", se posiciona contra alguien, sobre ella el choque aparece como consecuencia inevitable; en efecto, la frontera es una franja de territorio que conlleva la idea de frente: más allá se encuentra el enemigo, que puede retroceder o peligrosamente avanzar.

Lo mismo vale por el idioma italiano frontiera, por el francés frontière, por el inglés frontier. Y no es casual que el lema apareció por la primera vez en la época medieval y en la península ibérica: en el testamento del primer monarca de Aragón, Ramiro (1035-1063), redactado en 1059, se halla la frase "ad castros de fronteras de mauros qui sunt pro facere" ${ }^{\text {"; }}$ también en el siguiente testamento, de 1061, se dice "in castellos de fronteras de mauros qui sunt per fare et in castellos qui sunt in fronteras per facere"; finalmente, en otro texto de 1062 el rey alega: "et tu quod cavallero et franco sedeas quomodo homine debet esse in frontera francho et caballero". Así, relativamente al primer empleo de la palabra frontera se evidenció su significación semántica de ambiente militar, típico del poder del Estado; en la segunda acepción sirvió para especificar una línea de fortificación, pero en un espacio dinámico proyectado hacia el adversario mahometano; y, finalmente, el vocablo estaba vinculado a unas pautas necesariamente lejanas de esquemas prefabricados, características de una tierra de posible conquista y libertad (Du Cange 1844: 421) ${ }^{2}$.

El concepto y la palabra de acuñación hispánica de frontera, en su acepción esencialmente política y militar, desde los tiempos de la casa de Valois, pasaron al ámbito francés y entonces fueron aceptados y utilizados por los eruditos europeos. No fortuitamente en el idioma galo la "frontera" pasó a ser "confín” cuando Francia alcanzó sus límites geopolíticos "naturales", evitando así de expandirse, "signo que la edificación territorial, al menos por algunos, se había adquirido" (Nordman 1987: 52).

Sobre el testamento véase Philippe Sénac (2001).

2 En general, sobre la frontera española, sus identidades y representaciones en la época medieval, véase la interesante obra colectiva de Ayala Martínez, Buresi y Josserand (2001). Para el sistema imperial de la monarquía católica, sus dilatados márgenes y la "ciudadanía" véanse las recientes compilaciones de Bernabéu Albert (2010), Bernabéu Albert, Langue (2011) y Ciaramitaro, Puente Brunke (2017b). 
Regresando al mundo hispánico, en un reciente trabajo, Emilio Mitre Fernández (2015: 99-100) considera dos significaciones básicas de frontera y sus encuentros historiográficos: la primera imagina la frontera como "algo muy parecido a lo que se entiende en el presente: la línea que separa un Estado de otro"; la segunda analiza la frontera física: "en tanto delimita el alcance del poder de un Estado pero que refuerza esa naturaleza merced a factores de orden mental, ideológico, cultural"3. Así para el Medioevo hispánico, definitivamente desde Ramiro de Aragón, la frontera y sus zonas aledañas -espacios de civilizaciones al mismo tiempo en contraposición y en contacto pacíficohan generado sociedades organizadas por y para la guerra, imbuidas por un profundo espíritu caballeresco y venturoso.

Después de la batalla de las Navas de Tolosa (1212) inició la lenta conquista del valle del Guadalquivir, proceso que comportó la institucionalización en el reino de Castilla de una nueva figura: el adelantado mayor de la frontera o de Andalucía ${ }^{4}$. Frontera era una de las denominaciones que recibía Andalucía por hallarse junto al reino nazarí de Granada. Todo un ethos y unos principios jurídicos que se trasladaron a partir de 1492 a las Indias occidentales (Billington 1949).

Para Juan Carlos Arriaga-Rodríguez (2013: 9), en los siglos XVI y XVII el concepto jurídico de frontera sirvió para reafirmar el poder del soberano de España sobre sus posesiones imperiales: desde Europa y el Mediterráneo hasta el Pacífico, pasando obviamente por América. El objetivo del ensayo es dilucidar en el ámbito hispanoamericano, con alcance suprarregional, descriptivo y comparativo, el marco misionero fronterizo de Nueva España, pensado como espacio socio-histórico-geográfico todavía no conquistado de manera inquebrantable, desde los inicios de la colonización, en la primera mitad del siglo XVI, al 1767 (exilio jesuita) ${ }^{5}$. Para mostrar un cuadro indicador y un mapa de tres acciones misioneras en los márgenes indianos del imperio español en México, sus desemejantes metodologías y eficacias: la frontera chiapaneca, la región yaqui y el linde bajacaliforniano.

Quien escribe sostiene la tesis de la "enredada" polisemia del tema fronterizo, sin embargo, no excluye la posibilidad de alcanzar definiciones conceptuales y teóricas precisas, de sistematizar y encuadrar los diversos y complejos casos de la edad colonial; al mismo tiempo, se supone cuanto menos imprudente y desde luego relativista el juicio de los que apuntan a una insuperable
La frontera misionera en México entre conquista espiritual y territorial

Fernando Ciaramitaro

3 El historiador recuerda asimismo como pocas palabras como la de frontera se utilizan en el presente con tan renovadas aplicaciones (Mitre Fernández 2015: 101).

4 Pedro Ruiz de Olea fue el primer oficial en ostentar en 1253 el título de adelantado de la Frontera (González Jiménez 2004: 70).

5 Se trata así de un estudio descriptivo y comparativo. Justamente, como ha subrayado Alistair Hennessy (1978: 138), la comparación resulta una herramienta indispensable para elaborar similitudes y variables de cada región en la frontera. 
Dossier América Latina: fronteras y zonas fronterizas valla de una determinación canónica de sus acepciones en la especulación histórica y la historiografía ${ }^{6}$.

\section{Las fronteras en América e Hispanoamérica}

Desde 1776 la hazaña norteamericana hizo de la frontera, antes los montes Apalaches y el Misisipi, luego el inmenso oeste, una zona de paso y un territorio abierto para la ocupación, en el cual el enemigo era más bien la naturaleza salvaje y no el poblador autóctono: la frontera se transformó paulatinamente en una región poblada por hombres libres. Los historiadores norteamericanos fueron marcadamente influenciados por este concepto, que, a mediados del siglo XX, transmitieron a los europeos y a los iberoamericanos. Además, va recordado que, en los Estados Unidos, Frederick Jackson Turner fue el primero en considerar la frontera como un válido sujeto historiográfico y a dedicar un libro al tema, también si centrado solo en la historia de su país y sobre el significado que tal noción había tenido en aquel contexto histórico (Turner 1921: $1-38)^{7}$. Su tesis acerca de la idea de frontera condicionó historiadores europeos que estudiaban realidades políticas completamente diferentes: así fue el caso de Paul Wittek (1938) y sus investigaciones sobre el origen del imperio otomano o de Claudio Sánchez-Albornoz (1943; 1983), sobre la "reconquista" cristiana en la península ibérica y la empresa americana. Mientras que, paradójicamente, sus conclusiones no tuvieron el mismo efecto en la historiografía iberoamericana, que, generalmente, ha rechazado su juicio acerca de la "frontera móvil" (Blancpain 1990). Asimismo, el patrón misional religioso y el tipo de asentamiento elaborado por los españoles en la conquista aportaron "más complejidad al fenómeno de la construcción de la frontera imperial hispana de lo que muestra el paradigma turneriano" (Mantecón Movellán, Truchuelo García 2016: 22).

A partir de los años sesenta del siglo XX, el tema de la frontera en el espacio imperial español ha sido también objeto de variados estudios y, en particular, en los últimos quince años se han multiplicado de manera exponencial las investigaciones que, desde disímiles enfoques y aplicando nuevas técnicas, han contribuido a llenar las lagunas en la materia ${ }^{8}$. Como ha recordado

6 Véase, por ejemplo, el estudio de Hebe Clementi (1986-1988, vol. 1: 14): “[...] el concepto de frontera, una especie de vacío y de indefinición acompaña su existencia, que ninguna definición ni delimitación canónica logra cubrir".

7 Además, fue siempre Turner quien, entre fines del siglo XIX e inicios del XX, destacó cómo la democracia en los Estados Unidos se forjó gracias al fenómeno de la frontera, o sea, la movible línea fronteriza que se iba desplazando hacia el oeste, un espacio de importancia estratégica en la conformación de la democracia estadounidense (Ciaramitaro, Puente Brunke 2017a: 15).

8 Es extraordinario el avance realizado en las últimas dos décadas y si Bernd Schröter (2001: 351) pudo escribir hace diecisiete años que “[...] es característico hasta hoy en día que en lo referente a la ocupación de los antiguos territorios españoles y portugueses existan pocos 
Bernard Vincent (2017: 13), las cuestiones fronterizas resultan inagotables. Así, en el presente, las miradas analíticas se encauzan en múltiples canales y la frontera (o las fronteras) presentada por los especialistas es territorial, étnica, geopolítica, religiosa, de tolerancia o arraigada en prejuicios, social, económica, cultural, de género, artística, lingüística o psicológica, es un espacio que combina circunstancias plurales (Truchuelo, Reitano 2017: 17-18) ${ }^{9}$. Tomás A. Mantecón Movellán y Susana Truchuelo García (2016: 20) han aclarado brillantemente el complejo polimorfismo fronterizo en el contexto del sistema imperial español:

La idea de frontera que resulta fértil para el análisis histórico de la realidad de la Monarquía Hispánica es una noción polisémica en los espacios, tiempos y contextos. Las fronteras han tenido una dimensión histórica y se expresan como escenarios controvertidos, por cuanto separan y permiten que se muestren alteridades diferenciadas en interacción. En ocasiones se diluyen para configurar territorios o entornos más amplios, o se refuerzan en los bordes para acentuar la identidad del conjunto integrado y protegido con respecto a otros limitrofes. Se han conformado geográfica y cartográfica, jurídica, militar y culturalmente por usos y convenciones sociales, debido al autorreconocimiento y a la percepción de la alteridad entre comunidades separadas por la fe, la etnia o la jerarquía social, el género o incluso la edad. Han adoptado forma en limes imperiales, fronteras internas y mentales, confines de la conciencia, del entendimiento o de la tolerancia. También se han mostrado más abiertas o más cerradas, más o menos porosas o permeables y simbólicas.

Las fronteras del imperio surgieron para representar un determinado medio y sus tipologías fueron evolucionándose al ritmo de los cambios que se iban produciendo en las provincias y en las sociedades que definían (Ciaramitaro, Puente Brunke 2017a: 15). El proceso de construcción imperial de los reinos de Castilla y Aragón, a través de la lenta incorporación de principados, marcas e islas, antes en la península ibérica y el Mediterráneo, después en el Atlántico, en las Indias y hasta el Pacífico y Filipinas ${ }^{10}$, comportaron una

trabajos que -partiendo de una perspectiva continental-intenten concebir a la 'frontera', con sus semejanzas y diferencias regionales, como una problemática relativamente independiente del desarrollo social", las más actuales pesquisas han cambiado totalmente la perspectiva historiográfica, logrando resultados sugerentes y originales. Y también en las demás ciencias sociales el significado de frontera se ha ampliado notablemente y ahora su estudio cobija diferentes disciplinas (Bonnett Vélez 2016: 13).

9 Hasta por lo menos las independencias, cuando estos espacios fronterizos se transformaron en confines internacionales y se impuso el paradigma dieciochesco del moderno estado nacional (Sahlins 1996: 51-53).

${ }^{10} \mathrm{El}$ archipiélago filipino fue una verdadera frontera abierta o "frontera más allá de la frontera”, o sea, una frontera activa pero regresiva, véase García-Abásolo (2011).
La frontera misionera en México entre conquista espiritual y territorial

Fernando Ciaramitaro 
Dossier América Latina: fronteras y zonas fronterizas continua redefinición del espacio, un movimiento constante de fronterización, de anexión, abandono, recuperación territorial, definitivo asentamiento, que, en complicidad con las poblaciones autóctonas o en contraste con ellas (la guerra), concretó las regiones liminares y el confín.

En Norteamérica los difíciles escenarios climáticos y geográficos del límite novohispano, aunados a su lejanía de los centros de poder, a los pésimos y lentos canales de comunicación ${ }^{11}$, a la escasez de los recursos locales, eran condicionantes ineludibles de los contactos (a menudo muy pobres) de las comunidades que operaban en el área fronteriza (Johnson Black 1995: 159-163). Dicho esto, es evidente como en México, con el proceder de la expansión española, se concretaron diferentes tipologías de fronteras. Entre ellas, por ejemplo, adquirió un papel importantísimo la "frontera minera" del norte, caso clásico en América de asentamiento extensivo poblacional, en el cual el impulso por los metales preciosos determinó un audaz fenómeno migratorio (Hennessy 1978: 73-75; Gerhard 1982: 6-11). La historiografía habla a propósito de "frontera en movimiento" (Hennessy 1978: 102-108) o frontera in crescendo.

Sin embargo, para el estudio que se presenta al lector, la región liminar analizada es la frontera misionera, que metodológicamente se define por su semblante temporal, por la búsqueda de la autosuficiencia (a veces fallida) y por su cercanía con otras realidades fronterizas, la de los nativos y la de los soldados, como para el caso novovizcaíno. Como ha puntualizado Bernd Schröter (2001: 383), "Grandes distancias y el aislamiento espacial, necesidades estratégicas crecientes y, en parte, una marcada dinámica propia, son momentos claves y característicos de la colonización de las misiones, sobre todo en la parte occidental de la frontera norte de la Nueva España”, en particular en la Alta California (Jackson 1991).

Indudablemente para la "conquista" religiosa se ha empleado en larga escala el lema de frontera, muchas veces como espacio de la catolicidad, por la propaganda y las acciones del papado para mover en adelante los límites confesionales en las regiones americanas. En los siglos de la colonización, en efecto, iglesia y corona españolas han caminado unidas en esta ruta (Bolton 1917; Jiménez 2006: 191-251; Hausberger 2015: 93) $)^{12}$, con el objetivo de reforzar sus identidades; la tutela de las fronteras de la fe reforzó la identidad cultural, como lo evidencia de manera ejemplar el caso hispánico (Muto 2014: 15). Heinz Schilling (2001: 27) ha recalcado que:

11 Por ejemplo, en la primera mitad del siglo XVII se empleaban seis meses para viajar de México a Santa Fe, aproximadamente el mismo tiempo necesario para llegar en barco de Manila a Acapulco, el famoso tornaviaje (García-Abásolo 2011: 79-80).

${ }_{12}$ Alfredo Jiménez (2006), en una sugerente síntesis acerca de la frontera imperial del "Gran Norte” de México, ha hablado de una estrecha relación entre ambas esferas: corona e iglesia tenían un poder compartido en la expansión y consolidación de las fronteras. En efecto, el contexto feudal de la sociedad ibérica -las creencias y los mecanismos de acción de individuos y grupos- fusionó los objetivos políticos y religiosos (León Zavala 2001). 
This early identification of dogmatic purity as defined by the papal church with national consciousness explains the amazing immunità of the Spaniards as a people to the Reformation, as compared with the rest of Europe. It also explains the identification of national interests with those of modern confessionalist Catholicism, which became a matter of course at the end of the sixteenth century and continued down through the nineteenth and twentieth centuries.

En los tres siglos coloniales, franciscanos, dominicos, agustinos y los jesuitas en sus misiones y reducciones -a veces en competición entre ellosplasmaron un espacio dilatado en regiones connotadas por su empuje fronterizo. Las tierras misionales conformaban confines no solo en las relaciones entre predicadores e indígenas, sino también entre estos, el comercio, las mercancías, los mercados y los beneficios de otros colonizadores y oficiales de la monarquía. A partir de la segunda mitad del siglo XVIII, a este enmarañado universo de intereses se agregó el riesgo de un roce fronterizo con otras potencias europeas: ingleses y rusos empezaron a presionar en el norte y en Centroamérica.

Para los curas al servicio del rey español, dispuestos a luchar contra la superstición e instaurar así la verdadera religión en el Nuevo Mundo, la frontera era un panorama sin fin, un paraje etéreo hacia el cual proyectarse, que, sin embargo, punteaba nuevas y remotas metas de victoria de la fe (Mantecón Movellán 2012).

\section{Tres fronteras misionales de la Nueva España: Chiapas, la región yaqui y California}

En este apartado se analizan tres fronteras relacionadas con el mundo político-religioso de las misiones novohispanas. Tres realidades fronterizas que tuvieron métodos evangelizadores diferentes y específicas condiciones de operación: los dominicos y su acción misional en Chiapas; los jesuitas y sus prácticas catequísticas en dos regiones norteñas, el territorio yaqui y las Californias.

El patronato regio en las Américas aseguraba que la iglesia funcionara como auxiliar de la monarquía y convertía al clero en una rama más del "servicio civil", fiel y obediente a los mandatos reales (León Zavala 2001: 294). El patronato indiano, además, permitía el establecimiento y la realización de misiones, de parroquias, de diócesis, de obispados y delimitaba sus territorios. Aunque los religiosos poseían políticas propias, también eran operadores de los planes del Consejo de Indias, de hecho, el establecimiento de nuevas misiones requería su consentimiento. Así las misiones sirvieron también para fijar los lindes imperiales y, por ende, en la expansión misional, dominicos e ignacianos ejecutaron al menos tres voluntades: la real, la papal y la propia. A veces en concordancia,

La frontera misionera en México entre conquista espiritual y territorial

Fernando Ciaramitaro 
Dossier América Latina: fronteras y zonas fronterizas otras en fuerte contraste ${ }^{13}$. Y, en consecuencia, los indios sufrieron una difícil contradicción: por un lado, la corona fue atenta al bienestar de sus súbditos indianos, favoreciendo la cristianización y la castellanización, por otro no quiso comprometerse cabalmente en la economía, sino, al contrario, aprovechar su imperio ultramarino (Reinhard 1995: 20). En este espinoso contexto político y socioeconómico operaron los religiosos en las misiones ${ }^{14}$.

El ensanchamiento fronterizo mexicano de la orden de santo Domingo de Guzmán abarcó regiones menos extensas que las de los franciscanos. Llegados a la Nueva España en 1526, los dominicos se diseminaron por las provincias centrales del reino -en el valle de México, en Puebla, en Cuernavaca- y en las zonas mixteca, zapoteca (Ricard 1986: 146-147), chiapaneca y del Soconusco. En Chiapas, como es notorio, operó la figura carismática de Bartolomé de las Casas.

Los paganos de Chiapan ${ }^{15}$, los chapanecas, en el relato de los cronistas de la conquista, se representaban como una comunidad característicamente belicosa. A la venida de los europeos, vivían más de 4000 familias en la ciudad principal de su territorio, en casas muy sencillas pero funcionales. Aproximadamente en veinte años (1523-1544), la coacción española en la región fue total y concluyente: los militares impusieron ideas y hábitos extraños (Vos 1997: 56), consolidando la frontera meridional. Las reducciones de las cuantiosas aldeas indígenas en un número mucho más limitado de pueblos -los misioneros suponían que la diseminación de la etnia impedía cualquier estructura firme - y la guerra a fuego y a sangre ${ }^{16}$, las enfermedades, la esclavitud ${ }^{17}$, las deportaciones, el hambre y las malversaciones de la supuesta pacificación disminuyeron la población nativa en más de un 75\% (Gerhard 1991). Fue una verdadera hecatombe.

No obstante la persistente y polifacética resistencia aborigen, la fijación marcial de la frontera en la Mesoamérica suroccidental comportó una forzosa aculturación, que significó la quiebra de una parte considerable de la identidad

13 Guillermo Wilde (2009) demuestra, para el caso guaraní, que los misioneros llegaban incluso a negar las prerrogativas de la autoridad regia.

14 Persiguiendo su apostolado, los misioneros realizaron esfuerzos enormes para conocer las culturas locales, pero, asimismo, para percatarse de la "enfermedad" de la cual se quería sanar el "paciente", el indio. Se deseaba comprender los "diversos" para poderlos dominar. También es cierto que los autóctonos supieron apreciar el enriquecimiento que, gracias a las especies europeas, pudieron recibir en sus crías o en la caza en las praderas americanas (Reinhard 1995: 53-54). De todas estas contradicciones hay pruebas en la disputa sobre los llamados "títulos justos", en el debate político-teológico de las leyes de Burgos (1512) y de la junta de Valladolid (1550-1551) y en la confrontación entre Bartolomé de las Casas y Juan Ginés de Sepúlveda (Ciaramitaro 2017).

${ }^{15}$ Chiapan o Tepechiapan son los nombres con los cuales se designa al territorio de la antigua población indígena de los chiapanecas.

${ }^{16}$ La fórmula "guerra a fuego y a sangre" es la empleada por Philip W. Powell (1996) para la lucha chichimeca, sin embargo, puede también ser apropiada para el contexto de la anterior conquista chiapaneca.

${ }_{17}$ El régimen esclavista implantado por los españoles en Chiapas resulta efectivo desde el año 1528 (AGNM, Ramo civil, vol. 1276). 
originaria: el sistema de repartición del trabajo y de la tierra, las relaciones interpersonales, sus creencias, sus fiestas etcétera (Vos 1997: 65-75). A partir de 1544, los dominicos que llegaron a Chiapas para remediar a las destrucciones de los soldados -antes en calidad de misioneros, luego como doctrineros, con su longa manus de fiscales y sacristanes- desplegaron todo un eficaz arsenal católico de símbolos, credos, rituales, fiestas (el carnaval) y devociones (el santo patrono de la villa) que consolidó la sociedad hispana-indígena en la región y perduró ceteris paribus hasta la segunda parte del siglo XIX.

En Chiapas, gracias a la labor de los predicadores y por el espíritu y la pujanza de las Leyes Nuevas de 1542, que permitieron, en parte, castigar los abusos $^{18}$, se fundaron nuevas ciudades, barrios de indios y toda la población de la región se fraccionó en seis grandes áreas pastorales. A través de un sistema complejo de visitas, se fortaleció la frontera chiapaneca, modificándose el mapa geosocial de la entidad y creándose una original comunidad apostólica. Como ha reiterado Jan de Vos (1997: 110):

[...] los frailes fomentaron entre la población nativa el surgimiento de más de un centenar de diminutas naciones que motu proprio desarrollaron fronteras internas en los niveles religioso, cultural, político y étnico.

En 1560, después de diez años de haber comenzado, la reducción era una realidad en por lo menos cuatro de las seis zonas pastorales encomendadas a los dominicos.

Los predicadores tuvieron un asombroso éxito de evangelización, empero también cultural -aprendiendo sus idiomas y las costumbres-, de producción artesanal y agropecuaria -generando nuevos cultivos en el campo y criando animales europeos-, en la arquitectura -erigiendo edificios para el culto o trasformando los antiguos templos paganos en iglesias y conventos-; sin embargo -y esta fue la otra cara de la conquista espiritual y material de la frontera-, alteraron la vida indígena y, en muchas aldeas, el "servicio" pastoral se degeneró en explotación y los abusos del siglo XVII fueron excesivos (de ellos permanecen numerosas huellas en los archivos) $)^{19}$.

Terminada la conquista de Mesoamérica y emprendida la fase colonizadora, con la búsqueda de las riquezas minerales los europeos penetraron

18 Algunos encomenderos perdieron sus privilegios, otros fueron condenados a grandes multas para recompensar los nativos vejados. Las Leyes y ordenanzas nuevamente hechas por su majestad para la gobernación de las Indias y buen tratamiento y conservación de los indios, conocidas como Leyes Nuevas, son unas normas promulgadas por la corona para mejorar la condición de vida del indo, esencialmente a través de la revisión del sistema de la encomienda y la abolición de la esclavitud. Ellas consagraron una serie de derechos irrenunciables. Sobre el contenido de las Leyes Nuevas y la recepción en Chiapas de la legislación entre los conquistadores locales, véase Nélida Bonaccorsi (1990: 40-47).

19 Entre muchos ejemplos posibles, véanse los papeles del visitador José de Scals de 1691 (AGI, Audiencia de Guatemala, leg. 215).
La frontera misionera en México entre conquista espiritual y territorial

Fernando Ciaramitaro 
Dossier América Latina: fronteras y zonas fronterizas gradualmente hacia el norte, trazando las primeras rutas de asentamiento, por el deseo de ensanchar la frontera en una zona definida por poblaciones indígenas de agricultores numéricamente muy escasas y por condiciones climáticas ásperas. El medio natural era, en efecto, desértico. Por estas razones geográficas peculiares, por la resistencia indígena y no obstante el replanteamiento de las relaciones jurídico-administrativas del territorio, el septentrión novohispano representó un reto para la monarquía, sobre todo en el último siglo de la colonia (Amaya Palacios, Restrepo Zapata, Grajales González 2016: 32).

Según el diseño colonizador y misionero de la corona, a los jesuitas se le asignó el territorio comprendido entre Zacatecas, el norte de Nayarit, Durango, el norte de Sinaloa, Sonora, las Californias, luego hasta El Paso y Nuevo México y, hacia el oriente, la sierra de Chihuahua ${ }^{20}$. Y a pesar de que en las últimas dos décadas del siglo XVII y principios del XVIII las misiones septentrionales habían experimentado un auge, del que son ejemplos la ocupación de las Californias y la Pimería, la cristianización fue muy lenta.

La misión en la región yaqui empezó en 1591, cuando llegaron los primeros evangelizadores de la Compañía de Jesús: Gonzalo de Tapia y Martín Pérez. Ayudados por el estamento castrense, ya en la primera década del siglo XVII, se avasallaron los mayos y se emprendieron los primeros tratos con los yaquis, pueblo amerindio que vivía a lo largo de los 410 kilómetros del río homónimo.

Después de unas repetidas derrotas militares españolas, fueron los yaquis a solicitar, desde una relación de fuerzas que les favorecía, la venida de predicadores: en 1617 arribaron los padres Andrés Pérez de Ribas y Tomás Basilio, escoltados por cuatro nativos zuaques del río Fuerte, que les servían de colaboradores. Los yaquis recibieron bien a estos jesuitas que llegaron sin huestes y que, por eso mismo, se diferenciaban marcadamente de los conquistadores. De las ochenta rancherías existentes se procedió a "reducir" los yaquis y en 1623 ya se habían constituido ocho aldeas: Belem, Huíribis, Rahum, Potam, Vicam, Torim, Bacum y Cócorit (Gouy-Gilbert 1985: 23-52). Se reformuló el esquema de acción de los ignacianos: el acercamiento de los misioneros conllevó un sincretismo religioso y sociocultural que permitió la sobrevivencia de la comunidad autóctona, que pudo así dirigir su evolución y el proceso de integración a la sociedad hispánica que los jesuitas presentaban como modélica. O sea, se dio el camino contrario, de incorporación voluntarista de la frontera, del extraño, en el universo de los colonizadores. Se designaron yaquis a los oficios gubernamentales y ambos lados, misioneros e indios, salvaguardaron los compromisos sociopolíticos.

La evangelización de los indios conllevó no solamente bautizos e instrucción religiosa masiva, además se escogieron algunos yaquis para ser temastianes, o sea, catequistas, encargados de transmitir el saber que recibían de

${ }^{20}$ La encomienda misional de los jesuitas no excluía las antiguas instancias de los franciscanos para la conversión de los californios, BNM, Archivo franciscano, 3-38.1, ff. 1-2. 
los jesuitas a las nuevas generaciones. Se garantizaba así continuidad también para la formación de los creyentes y se conformaba una nueva elite que, inevitablemente, dio lugar a una organización jerárquica que, hasta aquel entonces, era ajena a la colectividad yaqui.

En una vasta comarca de aproximadamente 2000 kilómetros cuadrados y no obstante un proceso misionero de deterioro a partir de 1681 (Almada Bay, Medina Bustos, Valle Borrero Silva 2007: 239), solamente en el primer cuarto de la centuria dieciochesca llegaron a la región yaqui los primeros colonos hispánicos, con su régimen civil (Brown Villalba 1982: 559) ${ }^{21}$. Sin embargo, la "independencia relativa" de las tribus yaquis respecto a los iñiguistas y a los demás españoles siguió siendo única. Y el experimento yaqui del norte mexicano correspondía, también cronológicamente, al complejo diseño utopista de la Compañía en las reducciones paraguayas (Gouy-Gilbert 1985).

La colonización de la California se dio por la tarea de ignacianos y franciscanos. No obstante repetidas tentativas habían fracasado desde Hernán Cortés, solo en 1696 al jesuita Juan María Salvatierra se dio licencia para misionar en la península. La presencia de la orden de Loyola en el noroeste, en Sonora y Sinaloa, colocó los ignacianos en una posición de ventaja para pretender la integración de las Californias a la frontera misional que se estaban esforzando de irradiar (López Sarrelangue 1968; Río 1990: 64, 66, 79-80, 100-101). El virrey José Sarmiento de Valladares autorizó así la reducción de los gentiles a la verdadera fe, encomendando la empresa a los jesuitas ${ }^{22}$.

Bajo el mando de Salvatierra, la pequeña expedición de una barca y una galeota, protagonizada por cinco europeos, tres indígenas y un mulato, desembarcó en la región y empezó en Loreto la experiencia misionera (1697). Durante setenta años la Compañía de Jesús fundó numerosas misiones que, desde 1767, con el destierro de la orden, sirvieron a los franciscanos como base logística para los asentamientos de la Alta California (misiones, fuertes, pueblos). La ocupación fronteriza de las Californias se configuró como "zonal”, o sea, con un límite que avanzaba "conforme lo requiere la estrategia de una colonización progresiva y de control” de parte de los iñiguistas. De esta manera no se sujetaron todas las partes y se progresaba dejando regiones no atractivas del medio colonizado, conformándose un asentamiento fronterizo de explotación y no de poblamiento (Messmacher 1997: 36-37).

Sin embargo, desde la vertiente política, la actividad misionera de la Compañía en California se definió por su excepcionalidad: los padres tenían poder absoluto de control político, militar y jurisdiccional. Una soberanía plena que se otorgó por excluir la real hacienda del gasto que el proceso de expansión fronterizo conllevaba. Se conformó, de facto, un verdadero

21 Una "mirada nueva" a la población civil y presidial en Sonora se puede leer en Almada Bay, Medina Bustos, Valle Borrero Silva (2007: 254-259).

22 AGNM, Californias, vol. 63, ff. 15-19.
La frontera misionera en México entre conquista espiritual y territorial

Fernando Ciaramitaro 


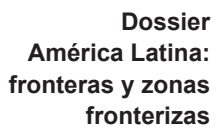

régimen político tendente a la teocracia, acompañado por un sistema de tenencia de la tierra que David Piñera Ramírez (1991: 46-47) ha definido como "posesión misional":

[...] se levantaba una organización jerárquica, en la que la autoridad superior residía en los misioneros; [...] los religiosos tenían facultades para nombrar personas que administraran justicia y optaron por delegarla en los militares, quienes desempeñaban la función siguiendo, en el fondo, las directrices que aquéllos les marcaban (Piñera Ramírez 1991: 49).

Como demuestra la documentación existente ${ }^{23}$, los jesuitas de la Baja California, a través de un discurso político-evangélico de expansión de la frontera católica hacia el norte novohispano, aplicaron un régimen jurídico extraordinario, que conformaba un grupo de "electos" como único responsable de la economía, la administración y el trabajo de los indios, condición que, en términos de posesión de la tierra, generó un sistema comunitario para su producción. El usufructo colectivo y dominical de la tierra expresaba el deseo teocrático de la Compañía: plasmar el paraíso de los elegidos en el Nuevo Mundo ${ }^{24}$.

\section{Comparaciones y conclusiones}

Las tres muestras observadas de extensión y consolidación (o su relativo fracaso) del poder del rey de España en las fronteras de México -Chiapas, territorio yaqui y California- se desarrollaron en momentos temporales de diferente duración: mientras que el primero, maniobrado por los dominicos, fue relativamente corto, de 1544 a 1560-1565, cuando las reducciones fueron realidad operante en cuatro de las seis regiones pastorales chiapanecas encargadas a los frailes (el proceso se cerró en 1575, con el apoyo franciscano y secular); en el caso de los jesuitas los tiempos fueron más dilatados.

En la zona yaqui, el contacto con los autóctonos y la región principió en 1591-1617 y se concluyó a finales del siglo XVII, cuando arribaron los primeros pobladores españoles y criollos. O sea, una centuria de faena misionera y afirmación fronteriza ininterrumpidas. En California la experiencia de la frontera ignaciana duró setenta años: en 1696 los jesuitas recibieron el mandato de misionar en la península, labor que empezaron sin poder terminar por el inesperado decreto de expulsión de la Compañía de todas las provincias del imperio en 1767. Sin embargo, tampoco en este prolongado periodo llegaron

\footnotetext{
23 AGNM, Provincias internas, vol. 7, ff. 69-93.

24 Como ha recalcado Piñera Ramírez (1991: 60), la posesión comunal jesuita retrasó la colonización civil y, consecuentemente, la conformación de la propiedad privada de la tierra en la provincia.
} 
contingentes poblacionales de compensación para el crecimiento del número de colonos en la región (Cuadro 1).

En términos sociopolíticos la afirmación de la frontera también tuvo secuelas disparejas: en el caso de Chiapas, después de dos décadas de guerras y destrucciones, protagonizadas por el estamento soldadesco, los frailes dominicos lograron consolidar las reducciones, sin embargo, a través de una enérgica aculturación, lastimosamente desapareció la mayoría de los rasgos identitarios que habían caracterizado la vida cotidiana de los indios originarios. No obstante $-\mathrm{y}$ desde una posición igualitaria respecto a los militares-, los predicadores lograron pacificar e incorporar la frontera meridional al sistema imperial del virreinato, a través de un incisivo avasallamiento de los aborígenes.

\begin{tabular}{ll}
\hline Regiones de labor misionera (frailes) & Periodo de consolidación de la frontera \\
\hline Chiapas (dominicos) & De 1544 a $1560-1565$ \\
\hline Territorio yaqui (jesuitas) & De 1591-1617 a $1700 \mathrm{c}$. \\
\hline California (jesuitas) & De 1696-1697 a 1767 \\
\hline
\end{tabular}

Fuente: Elaboración del autor.

En la región yaqui se asistió a una peculiar situación. De acuerdo con los brazos militar y civil, los jesuitas tuvieron que aplicar una estrategia de compromiso aceptando sincréticamente numerosas costumbres nativas que, por la imposibilidad de una victoria de las huestes españolas, definieron una anexión voluntarista del límite fronterizo. Y no obstante el intercambio fuese desigual - puesto que el conocimiento aportado por los religiosos fue determinante en la elaboración de la nueva coexistencia-, los yaquis se apropiaron de aquel discurso y de aquella praxis de organización social y consideraron el resultado como patrimonio propio. Fue el "colonizado" quien se incorporó al espacio ocupado también por el europeo.

En la península californiana se dio una circunstancia aún más excepcional: los ignacianos fueron los delegados regios de una soberanía absoluta que, en términos organizativos y factuales, dispuso un régimen casi teocrático de subordinación de los oficiales a la voluntad de la jerarquía eclesial (Cuadro 2).

\begin{tabular}{ll}
\hline Chiapas (dominicos) & Igualitaria \\
\hline Territorio yaqui (jesuitas) & Igualitaria \\
\hline California (jesuitas) & Poder superior \\
\hline
\end{tabular}

Fuente: Elaboración del autor.

A través de esta muestra representativa de la frontera misional en México, queda evidente como los lindes no fueron únicamente espacios de aculturación, sino lugares de múltiples relaciones y enlaces, de biunívocas y complejas
La frontera misionera en México entre conquista espiritual y territorial

Fernando Ciaramitaro

\section{Cuadro 1.}

Regiones fronterizas misionales y periodos de consolidación
Cuadro 2.

Relación fronteriza de los misioneros con los estamentos civil y militar 
Dossier América Latina: fronteras y zonas fronterizas correspondencias entre locales y extraños (Johnson Black 1995: 158-163). Los hombres de las fronteras novohispanas han interactuado en el espacio a través de variados lenguajes, la lengua del pacto o de la guerra, del comercio o de la familia, del cultivo o de la ganadería, y así como iba progresando la ocupación de tierras de conquistadores y pobladores, estos se fueron adaptando a las diversas condiciones climáticas, geográficas, sociales, políticas y culturales con las cuales, a lo largo de tres siglos, se fueron desafiando.

\section{Referencias bibliográficas}

Almada Bay I., Medina Bustos J.M., del Valle Borrero Silva M. (2007), Hacia una nueva interpretación del régimen colonial en Sonora. Descubriendo a los indios y redimensionando a los misioneros, 1681-1821, "Región y Sociedad", vol. 19, no especial, pp. 237-266.

Amaya Palacios S., Restrepo Zapata J.D., Grajales González H.F. (2016), La frontera norte novohispana y la resistencia indígena, 1763-1785, "Vegueta. Anuario de la Facultad de Geografía e Historia", no 16, pp. 31-50.

Arriaga-Rodríguez J. C. (2013), Tres tesis del concepto frontera en la historiografía, en: Tres miradas a la historia contemporánea, G. Gurza Lavalle (coord.), Instituto Mora, México, pp. 9-47.

Ayala Martínez C. de, Buresi P., Josserand P. (eds.) (2001), Identidad y representación de la frontera en la España medieval (siglos XI-XIV). Seminario celebrado en la Casa de Velázquez y la Universidad Autónoma de Madrid (14-15 de diciembre de 1998), Casa de VelázquezUniversidad Autónoma de Madrid, Madrid.

Bernabéu Albert. S. (coord.) (2010), Poblar la inmensidad: sociedades, conflictividad y representación en las márgenes del Imperio Hispánico (siglos XV-XIX), Rubeo-CSIC, Rubi.

Bernabéu Albert S., Langue F. (coords.) (2011), Fronteras y sensibilidades en las Américas, Doce Calles, Madrid.

Billington R. A. (1949), Westward Expansion: a History of the American Frontier, The Macmillan Company, Nueva York (en colaboración con J. B. Hedges).

Blancpain J.-P. (1990), Les araucans et la frontière dans l'histoire du Chili, des origines au XX siècle. Une épopée américaine, Vervuert Verlag, Frankfurt am Main.

Bolton H. E. (1917), The Mission as a Frontier Institution in the Spanish-American Colonies, "American Historical Review", vol. 23, pp. 42-61.

Bonaccorsi N. (1990), El trabajo obligatorio indígena en Chiapas, siglo XVI (Los Altos y Soconusco), Universidad Nacional Autónoma de México, México.

Bonnett Vélez D. (2016), Presentación del dossier "Una mirada histórica, teórica e historiográfica sobre la frontera", "Historia Crítica”, no 59, pp. 13-18.

Brown Villalba C. (1982), Sinaloa, en: El territorio mexicano, vol. II (Los estados), Instituto Mexicano del Seguro Social, México.

Ciaramitaro F. (2017), Lo Stato moderno tra guerra e pace nel pensiero politico ispanoamericano: dal medioevo al barocco, en: Alterità e cosmopolitismo nel pensiero moderno e contemporaneo, G. Magnano San Lio, L. Ingaliso (eds.), Rubbettino, Soveria Mannelli, pp. 53-76. 
Ciaramitaro F., de la Puente Brunke J. (2017a), Naturaleza, extranjería y fronteras entre historia e historiografía: una introducción, en: Extranjeros, naturales y fronteras en la América ibérica y Europa (1492-1830), F. Ciaramitaro, J. de la Puente Brunke (eds.), Universidad Autónoma de la Ciudad de México-Universidad de Murcia-Red Columnaria, México-Murcia, pp. 7-30.

Ciaramitaro F., de la Puente Brunke J. (eds.) (2017b), Extranjeros, naturales y fronteras en la América ibérica y Europa (1492-1830), Universidad Autónoma de la Ciudad de MéxicoUniversidad de Murcia-Red Columnaria, México-Murcia.

Clementi H. (1986-1988), La frontera en América, Leviatán, Buenos Aires, 4 vol.

Du Cange D. (1844), Glossarium mediae et infimae latinitatis, Firmin Didot, París, vol. III.

García-Abásolo A. (2011), Filipinas. Una frontera más allá de la frontera, en: Fronteras del mundo hispánico: Filipinas en el contexto de las regiones liminares novohispanas, M.M. Manchado López, M. Luque Talaván (coords.), Universidad de Córdoba, Córdoba, pp. 71-88.

Gerhard P. (1982), The North Frontier of New Spain, Princeton University, Princeton.

Gerhard P. (1991), La frontera sureste de la Nueva España, Universidad Nacional Autónoma de México, México.

González Jiménez M. (2004), Alfonso X el Sabio, Ariel, Barcelona.

Gouy-Gilbert C. (1985), Una resistencia india. Los yaquis, Centro de estudios mexicanos y centroamericanos, México.

Hausberger B. (2015), Miradas a la misión jesuita en la Nueva España, El Colegio de México, México.

Hennessy A. (1978), The Frontier in Latin American History, E. Arnold, Londres.

Jackson R. H. (1991), La colonización de la Alta California: un análisis del desarrollo de dos comunidades misionales, "Historia mexicana", vol. 41, no 1 (161), pp. 83-110.

Jiménez [Núñez] A. (2006), El Gran Norte de México. Una frontera imperial en la Nueva España (1540-1820), Tebár, Madrid.

Johnson Black N. (1995), The Frontier Mission and Social Transformation in Western Honduras. The Order of Our Lady of Mercy, 1525-1773, Brill, Leiden.

León Zavala J. F. (2001), El real patronato de la Iglesia, "Revista de la Facultad de Derecho de México", no 236, pp. 287-303.

López Sarrelangue D. E. (1968), Las misiones jesuitas de Sonora y Sinaloa, base de la colonización de la Baja California, "Estudios de Historia Novohispana", vol. 2, no 2, pp. 149-201.

Mantecón Movellán T. A. (2012), Sangre de santos, ¿semilla de cristianos?: espíritu misionero y martirio en la temprana Edad Moderna, "Revista Convergência Crítica", vol. 1, no 2, pp. 299-326.

Mantecón Movellán T. A., Truchuelo García S. (2016), La(s) frontera(s) exteriores e interiores de la Monarquía Hispánica: perspectivas historiográficas, "Historia Crítica", no 59, pp. 19-39.

Messmacher M. (1997), La búsqueda del signo de Dios. Ocupación jesuita de la Baja California, Fondo de Cultura Económica, México.

Mitre Fernández E. (2015), Los límites entre estados: la idea de frontera en el Medioevo y el caso de los reinos hispano-cristianos, en: El mundo de los conquistadores, M. Ríos Saloma (ed.), Universidad Nacional Autónoma de México-Sílex, México-Madrid, pp. 99-117.

Muto G. (2014), Introduzione. Mediterraneo, frontiere, identità, en: Identità e frontiere. Politica, economia e società nel Mediterraneo (secc. XIV-XVIII), L.-J. Guia Marín, M. G. R. Mele, G. Tore (eds.), F. Angeli, Milán, pp. 13-19.
La frontera misionera en México entre conquista espiritual y territorial

Fernando Ciaramitaro 


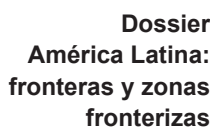

América Latina:

fronterizas
Powell P. W. (1996), La guerra chichimeca (1550-1600), Fondo de Cultura Económica, México.

Piñera Ramírez D. (1991), Ocupación y uso del suelo en Baja California de los grupos aborígenes a la urbanización dependiente, Universidad Nacional Autónoma de México, México.

Reinhard W. (1995), Lespansione europea. La conquista del Nuovo Mondo americano e dell'Antico Mondo asiatico, en: Storia d'Europa, vol. 4 (Letà moderna. Secoli XVI-XVIII), M. Aymard (ed.), Einaudi, Turín, pp. 5-55.

Ricard R. (1986), La conquista espiritual de México. Ensayo sobre el apostolado y los métodos misioneros de las órdenes mendicantes en la Nueva España de 1523-1524 a 1572, Fondo de Cultura Económica, México.

Río I. del (1990), A la diestra mano de las Indias. Descubrimiento y ocupación colonial de la Baja California, Universidad Nacional Autónoma de México, México.

Sahlins P. (1996), Frontières et identités nationales. La France et l'Espagne dans les Pyrénées depuis le XVII siècle, Belin, París.

Sánchez-Albornoz C. (1943), España y el Islam, Sudamericana, Buenos Aires.

Sánchez-Albornoz C. (1983), La Edad Media española y la empresa de América, Ediciones Cultura Hispánica del Instituto de Cooperación Iberoamericana, Madrid.

Schilling H. (2001), Confessionalisation and the Rise of Religious and Cultural Frontiers in Early Modern Europe, en: Frontiers of Faith. Religious Exchange and the Constitution of Religious Identities, 1400-1750, E. Andor, I.G. Tóth (eds.), Central European UniversityEuropean Science Foundation, Budapest, pp. 21-35.

Schröter B. (2001), La frontera en Hispanoamérica colonial: un estudio historiográfico comparativo, "Colonial Latin America Historical Review", vol. 10, no 3, pp. 351-385.

Sénac P. (2001), 'Ad castros de fronteras de mauros qui sunt profacere'. Note sur le premier testament de Ramire I d'Aragon, en: Identidad y representación de la frontera en la España medieval (siglos XI-XIV). Seminario celebrado en la Casa de Velázquez y la Universidad Autónoma de Madrid (14-15 de diciembre de 1998), C. de Ayala Martínez, P. Buresi, P. Josserand (eds.), Casa de Velázquez-Universidad Autónoma de Madrid, Madrid, pp. 205-221.

Spicer E. H. (1974), Culture contact and change in northwestern Mexico, en: Homenaje a Gonzalo Aguirre Beltrán, Universidad Veracruzana-Instituto Indigenista Interamericano, México, vol. 2.

Spicer E. H. (1980), The Yaquis: A Cultural History, University of Arizona Press, Tucson.

Truchuelo S., Reitano E. (2017), A propósito de Las fronteras en el mundo atlántico (siglos XVI-XIX), en: Las fronteras en el mundo atlántico (siglos XVI-XIX), S. Truchuelo, E. Reitano (eds.), Universidad Nacional de La Plata, La Plata, pp. 17-23.

Turner F. J. (1921), The Frontier in American History, H. Holt, Nueva York.

Vincent B. (2017), Prologo, en: Las fronteras en el mundo atlántico (siglos XVI-XIX), S. Truchuelo, E. Reitano (eds.), Universidad Nacional de La Plata, La Plata, pp. 13-16.

Vos J. de (1997), Vivir en frontera. La experiencia de los indios de Chiapas, Centro de Investigaciones y Estudios Superiores en Antropología Social-Instituto Nacional Indigenista, México.

Wilde G. (2009), Religión y poder en las misiones de guaraníes, Editorial SB, Buenos Aires.

Wittek P. (1938), The Rise of the Ottoman Empire, B. Franklin, Londres. 